4Young RR, Delwaide PJ. Drug TherapySpasticity. New Eng J Med 1981;304:28-33 and 96-99.

\section{Godwin-Austen and Corston reply}

We found Professor Young's letter most interesting, and would like to apologise for misquoting his important paper. But the implication of his comments must be that spasmolytic drugs such as baclofen, while demonstrably able to relieve the increased resistance to passive movement in the spastic limb, have no value in the treatment of patients whose complaint is one of difficulty with walking. We believe that these drugs are widely recommended for this purpose.

We were hesitant to conclude that baclofen (and DS103-282) has no value in the treatment of patients with spastic legs whose complaint is one of difficulty with walking, on the basis of a study of a small group. But we agree with Professor Young that where disturbance of gait is studied in spastic subjects it is difficult or impossible to demonstrate improvement attributable to these drugs.

RB GODWIN-AUSTEN RN CORSTON

\section{What should neurologists do?}

Sir: Your December Editorial and the paper by Fitzpatrick and Hopkins ${ }^{1}$ seem to predict an era when social esteem rather than professional excellence will come to dominate neurological practice and when, for much of the neurologist's day, hard clinical truth will have to give way to expansive symptomatic comforting. I doubt it. The opening of neurological clinics to all comers may have made the search for real illness more difficult but the search itself need not be engulfed by social irrelevance. Training "in the techniques of taking a careful history and of scrupulous physical examination" cannot be bettered for excluding organic illness with a minimum of fuss yet ensuring that the patient's symptoms are given a fair hearing. At the same time coincident, non-neurological ailments are likely to be recognised and suitably treated. The finding by Fitzpatrick and Hopkins $^{1}$ that patients made less demands on the family doctor after a hospital consultation is not without therapeutic meaning and will be quoted as a justification, both cost-effectively and socially, of such referrals. On the other hand their suggestion that the neurologist has a "minimal role" in the care of working-class patients with headache and psychiatric symptoms but a more exalted place in managing middleclass and dissatisfied migrainers seemed something of a non sequitur.

During 1977,1978 and 1979 approximately one-fifth of all my outpatients, drawn from a population of 1.5 millions served by two neurologists (Dr John Graham and myself), were referred with headache, blackout or dizzy spell as their prime symptom. When their records were reviewed in 1981 those with an introductory letter suggesting organic symptoms and those with a story of probable epilepsy were excluded from the tally and there remained 940 patients who were not expected to have a physical lesion. After interview and examination the majority were given appropriate advice and sent back to their doctor; some had simple tests-such as exclusion of anaemia, diabetes or myxoedema; a few had more sophisticated procedures including EEG and radiology; and an occasional patient was admitted to hospital for full investigation and therapy. A minority of those without physical disease were followed up as outpatients. No independent survey was made of the patients' reaction to their hospital visit but if this was thought to be unfavourable a note was added in the letter to the referring doctor. Dissatisfied patients and re-referrals were, by local arrangement, returned to me.

The accompanying Table refers to these 940 patients, presenting with headache, blackout or dizzy spell, who were examined exclusively by me and thus represent a cross-section of such patients in an open neurological clinic of industrial and rural South Wales. They indicate an annual referral rate of 42 per 100,000 population. The figures are the bones of this retrospective review. I have added some notes, based on more detailed break-down, to clothe these bare facts with sufficient canvas for a picture of this kind of consultation to emerge. In each group the second most common aetiology was "psychogenic". Whereas this section of the headache group was divided into three distinct entities (ten-
Table

197719781979 Total

\begin{tabular}{|c|c|c|c|c|}
\hline $\begin{array}{l}\text { Headaches } \\
\text { migraine } \\
\text { physical disorder } \\
\text { neurological } \\
\text { psychogenic }\end{array}$ & $\begin{array}{r}84 \\
27 \\
6 \\
52\end{array}$ & $\begin{array}{r}85 \\
33 \\
5 \\
33\end{array}$ & $\begin{array}{r}95 \\
28 \\
4 \\
45\end{array}$ & \\
\hline $\begin{array}{l}\text { Blackouts } \\
\text { fainting } \\
\text { systemic disorder } \\
\text { neurological } \\
\text { other } \\
\text { psychogenic }\end{array}$ & $\begin{array}{r}41 \\
5 \\
4 \\
17 \\
33\end{array}$ & $\begin{array}{r}156 \\
38 \\
7 \\
5 \\
12 \\
20\end{array}$ & $\begin{array}{r}172 \\
31 \\
6 \\
8 \\
7 \\
41\end{array}$ & 497 \\
\hline $\begin{array}{l}\text { Dizzy spells } \\
\text { peripheral vertigo } \\
\text { miscellaneous } \\
\text { central vertigo } \\
\text { psychogenic }\end{array}$ & $\begin{array}{r}31 \\
2 \\
10 \\
20\end{array}$ & $\begin{array}{r}29 \\
3 \\
16 \\
13\end{array}$ & $\begin{array}{r}27 \\
1 \\
7 \\
9\end{array}$ & 275 \\
\hline & 63 & 61 & 44 & 168 \\
\hline
\end{tabular}

sion, depression, psychosis), each with a therapeutic opportunity, no such division was made for patients in the two other groups with resultant imprecision and lack of firm advice. Here certainly was matter for reflection.

Of the 497 patients with headache in one patient only was tumour the cause, 14 others having a neurological disorder. These 15 patients contrasted with 88 whose headache was related to a nonneurological but physical illness. Among the migrainers seven patients had a story and/or signs of a stroke, severe and recurrent in one, related to the contraceptive pill although no mention of stroke or pill was made in the referring letter. As a result of this startling experience a doctor writing in about a headache-patient at risk for taking the pill is now warned at once by telephone and letter. A similar procedure has been adopted over the elderly unless the doctor has specifically excluded cranial arteritis. One patient previously examined two years after a head injury had then shown no abnormal signs and had had a normal skull radiograph and EEG. Referred a second time because of headache, nine years after the injury, he had a bony ridge from temple to mastoid, the outward sign of a calcified sub-periosteal haemotoma. Another patient with a 20-year history of cough headache was first examined in 1962. She had no signs and CSF, radiographs of the cranio-vertebral junction, and myelogram were all normal. When she returned in 1978 with persistent headache she had oscillopsia, facial numbness, gag areflexia and ataxia. Her 36-year-old headache was 